\title{
Kepemimpinan Kepala Sekolah Dalam Mengembangkan Kreativitas Dan Inovasi Pembelajaran Guru Pada Masa Covid-19
}

\author{
Putri Tobing ${ }^{1}$, Enung Hasanah ${ }^{2}$ \\ ${ }^{1}$ Manajemen Pendidikan, Universitas Ahmad Dahlan \\ ${ }^{2}$ Manajemen Pendidikan, Universitas Ahmad Dahlan \\ Kampus 2B UAD, Jalan Pramuka No 42, Umbulharjo, Yogyakarta \\ Email: putritobing1995@gmail.com
}

\begin{abstract}
Creativity includes new results. In general, teacher creativity has the main function of helping to complete work quickly and efficiently. The importance of teacher creativity in learning includes: (1) teacher creativity is useful in transferring more complete information, (2) teacher creativity is useful in stimulating students to think scientifically, (3) teacher creativity products will stimulate student creativity. The existence of creative teachers who will continuously emerge innovations in learning. The purpose of developing creativity in developing innovative learning is to describe and analyze the implementation of a more creative and innovative learning process. The roles of school principals in developing teacher creativity at SDN Napabalano are 1) principals who meet teacher needs; 2) The principal is with assistance (old teachers and young teachers); 3) the principal holds activities (training, workshops) related to the use of technology and other activities to develop teacher learning, especially during the current Covid-19 pandemic. 4) the principal carries out the evaluation and is always followed by follow-up activities on the evaluation results. .
\end{abstract}

Keywords: Principal role, teacher creativity, teaching innovation

Abstrak. Kreativitas meliputi hasil yang baru. Secara umum kreatifitas guru memiliki fungsi utama yaitu membantu menyelesaikan pekerjaannya dengan cepat dan efisien. Adapun pentingnya kreativitas guru dalam pembelajaran antara lain: (1) Kreatifitas guru berguna dalam transfer informasi lebih utuh, (2) Kreatifitas guru berguna dalam merangsang siswa untuk lebih berpikir secara ilmiah, (3) Produk kreatifitas guru akan merangsang kreatifitas siswa. Adanya guru kreatif yang terus menerus akan timbul inovasi dalam pembelajaran. Tujuan mengembangkan kreatifitas dalam mengembangkan pembelajaran yang inovasi untuk mendeskripsikan dan menganalisa pelaksanaan proses pembelajaran yang lebih kreatif dan inovatif. Peran kepala sekolah dalam mengembangkan kreativitas guru di SDN Napabalano adalah 1) kepala sekolah yang memenuhi kebutuhan guru; 2) Kepala sekolah adalah dengan adanya pendampingan (guru tua dan guru muda); 3) kepala sekolah mengadakan kegiatan (training, workshop) terkait penggunaan teknologi dan kegiatan lainnya untuk mengembangkan pembelajaran guru khususnya di masa pandemic covid-19 saat ini. 4) kepala sekolah melaksanakan evaluasi dan selalu diikuti oleh kegiatan tindak lanjut terhadap hasil evaluasi..

Kata Kunci: Peran kepala sekolah, kreatifitas guru, inovasi pembelajaran

\section{PENDAHULUAN}

Pada masa pandemic covid-19, diperlukan pikiran terbuka dan kreatifitas tinggi dari seluruh praktisi pendidikan, namun sifat konservatif dan masalitas pendidikan menjadi tantangan bagi masyarakat yang dipacu dengan IPTEK, hal ini dapat diimbangi dengan inovasi pembelajaran yang berbudaya. Paradigm dibutuhkan konsep inovasi pembelajaran tanpa mengganti secara keseluruhan system dan pengalaman pendidikan namun bersifat peningkatan, penyempurnaan dan pembaharuan (Puspitasari, 2016). Pembelajaran merupakan inti dari pendidikan, pemecahan masalah rendahnya kualitas pendidikan terfokus pada kualitas pembelajaran dimana pendidik adalah salah satu yang berperan penting dalam menentukan keberhasilan pembelajaran. Oleh 
karena itu, Pendidik yang baik adalah pendidik yang kreatif dan selalu mencari strategi baru dalam pembelajaran (Komalasari, 2010). Dalam konteks ini, kepala sekolah memiliki peran yang besar untuk dapat mengembangkan kemampuan dan kemauan guru untuk selalu mengembangkan inovasi pembelajaran.

Peran kepemimpinan khususnya pada dunia pendidikan menurut (Laihad, Hidayat, Rais. Yuyun El. Patras. Helena, 2018) dalam Peleg, 2012 bahwa dalam melakukan aktivitasnya seorang pemimpin pendidikan memerlukan pengetahuan, pengalaman, kesabaran dan waktu yang panjang dalam mencapai tujuan pendidikan, sejalan dengan (Moh. Rois, Fartika Ifriqia, 2017) bahwa kepala sekolah dalam kepemimpinanya diharapkan memahami keberadaan sekolah sebagai organisasi kompleks dan mampu melaksanakan peran dan tanggung jawab untuk memimpin sekolah dalam mencapai tujuan pendidikan nasional.

Tugas kepala sekolah sebagai pemimpin sangat kompleks, selain mengelola sekolah supaya menjadi efektif dan efisien secara khusus juga harus mampu meningkatkan kinerja guru dalam tugasnya khususnya pada pembelajaran (Sonedi et al., 2018), seperti mengelolah kurikulum dan bahan buku ajar, kepala sekolah juga diharapkan mampu memanajemen SDM guru, staff tata usaha, dan mengelola serta mengembangkan asset keuangan institusi (Fitrah, 2017). Pernyatan ini didukung oleh (Sukmaswati \& Profesional, 2019) bahwasanya kepala sekolah memiliki peran sebagai pemimpin di sekolahnya dan bertanggung jawab untuk memimpin proses pendidikan di sekolahnya, yang berkaitan dengan peningkatan mutu sumber daya manusia, peningkaan profesionalisme guru, karyawan dan semua yang berhubungan dengan sekolah dibawah naungan kepala sekolah.

Merujuk pada Surat Keputusan Menteri Penertiban Aparatur Negara Nomor 296 tahun 1996 tentang Jabatan Guru, dinyatakan bahwa kepala sekolah adalah guru yang mendapat tugas tambahan. Sumber daya pendidikan yang selalu menjadi sorotan publik selama ini adalah eksistensi guru dan perannya dalam lingkungan pendidikan (Manik et al., 2016). Kreativitas guru memiliki peranan penting dalam pelayanan pendidikan karena berkaitan erat dengan keberhasilan pembelajaran dikelas. Seorang pemimpin pada suatu lembaga sekolah yang menjadi panutan bawahannya, selalu memberi inspirasi dan motivasi akan sangat mempengaruhi kreativitas guru, karena guru diberi banyak kesempatan untuk mengembangkan ide-ide yang dimilikinya serta memfasilitasi mereka untuk mengembangkan ide atau gagasan mereka (Ghifar et al., 2019).

Guru yang aktif dalam mengembangkan ide-ide merupakan guru yang inovatif. Inovasi sebagai suatu gabungan antara proses penemuan (invention) dan eksploitasi (exploitation) (Wibowo \& Saptono, 2017). Pernyataan berikut didukung oleh (LambriexSchmitz et al., 2020) bahwa

"innovative work behaviour is a multi-stage iterative process in which employee behaviour targets the exploration ofopportunities, idea generation, idea promo- tion, idea realization and the sustainable implementation ofthese ideas, process- es, products or procedures within a role, a group or an organization, whereby the ideas are (relatively) new and intended to benefit the relevant unit odoption"

Hal tersebut sejalan denga napa yang dikemukakan oleh (Fitrah, 2017) bahwa inovasi pembelajaran adalah pembaharuan secara sengaja yang dilakukan oleh lembaga itu sendiri agar tujuan pembelajaran dapat tercapai, dan inovasi ini merupakan solusi untuk memecahkan suatu masalah yang dihadapi.

Inovasi yang dulakukan oleh guru dalam mengembangkan pembelajaran merupakan bukti dari adanya kreativitas guru. Pengajaran yang kreatif melibatkan guru dalam membuat pembelajaran menjadi lebih menarik dan efektif serta menggunakan pendekatan imajinatif di dalam kelas. Pengajaran kreatif adalah tentang kepribadian guru, kreativitas pribadi dan manifestasinya dalam praktik sehari-hari. Pengajaran untuk kreativitas menunjukan kemampuan guru dalam mengidentifikasi kekuatan kreatif anak-anak dan membantu untuk menumbuhkan potensi kreativitas anak agar dapat berkembang secara optimal (Lapeniene \& Dumciene, 2014). Seoang guru dapat menajdi kreatif ketika mereka memiliki kemampuan 
untuk melakukan keselarasan berpikir yang relevan denagn kebutuhan, memiliki kemampuan untuk menciptakan sesuatu yang baru dan menarik, mampu mengontrol semua kegiatan secara lebih sistematis, serta mampu melakukan inovasi pembelajaran yang meanrik bagi peserta didik (Craft et al., 2014)

Tinggi rendahnya kreativitas guru sangat tergantung pada kemampuan kepemimpinan sekolah dalam memberdayakan potensi yang dimiliki oleh para guru (Akert \& Martin, 2012). Terlebih pada masa pandemic covid-19 yang sedang terjadi saat ini, dimana semua proses pembelajaran hanya dapat dilaksanakan melalui pembelajaran jarak jauh (Çubukçu \& Aktürk, 2020). Oleh karena itu, penting untuk dilakukan penelitian-penelitian yang dapat mengungkapkan proses kepemimpinan kepala sekolah dalam meningkatkan kreativitas dan inovasi guru.

SDN 4 Napabalano merupakan salah satu dari 16 sekolah di Kabupaten Muna yang akan menjadi sekolah model acuan dalam standar mutu pendidikan (beritakendari.com., 2019). Hal itu menunjukan bahwa SDN 4 Napabalano memilki keunggulan dalam hal proses penjaminan mutu pendidikan, yang salah satunya berhasil membangun kreativitas dan inovasi pembelajaran di masa covid-19. Hal itu dapat menjadi best practices kepemimpinan sekolah yang berguna bagi sekolah-sekolah lain yang sedang menghadapi masalah dalam upaya mengembangkan kreativitas dan inovasi pembelajaran oleh para guru. Penelitian ini bertujuan untuk mengeksplorai proses kepemimpinan kepala sekolah dalam meningkatkan kreativitas dan inovasi guru di SDN 4 Napabalano.

\section{METODE}

Pada masa covid-19, penelitian langsung tidak mungkin dilakasanakan karena ada kebijakan social distance, oleh karena itu metode yang digunakan peneliti untuk menggali data dengan menggunakan wawancara virtual dengan kepala sekolah dan guru-guru di SDN 4 Napabalano. Proses pengumpulan data dilakukan pada bulan Nopember 2020. Seluruh data yang dihasilkan kemudian diolah dan dianalisis dengan metode analisis kualitatif (O'Connor . \&
Gibson, 2003). Langkah-langkah analisis data terdiri dari kegiatan mengelola data; menemukan dan mengorganisasi ide dan konsep; membangun tema menyeluruh dalam data; memastikan keandalan dan validitas dalam analisis data dan dalam temuan; menemukan penjelasan yang mungkin dan masuk akal untuk temuan; dan gambaran dari langkah-langkah terakhir.

\section{HASIL DAN PEMBAHASAN}

Berdasarkan hasil wawancara peneliti dan kepala sekolah SDN 4 Napabalano (20 November 2020) bahwa untuk mengembangkan inovasi pembelajaran guru tidak semudah yang kita pikirkan, dimana kepala sekolah harus mempunyai banyak referensi baik pengalaman kepala sekolah lain, dari buku, atau pengalaman diri sendiri yang dimodifikasi untuk diselenggarakan untuk pembelajaran berikutnya. Proses penerapan mengembangkan inovasi pembelajaran mengalami berbagai kendala salah satunya banyak guru yang kurang paham akan IT, kurangnya sarana dan prasarana, kurang percaya diri akan ide-ide yang mereka dapatkan sehingga mengalami kesulitan saat mengarahkan siswa mengidentifikasi masalah. Untuk menghadapi kendala-kendala tersebut kepala sekolah sebagai pemimpin di lembaga sekolah tersebut mengeluarkan berbagai kebijakan untuk mencapai mutu pendidikan khususnya mengembangkan inovasi pembelajaran guru.

Dari berbagai kebijakan tersebut, kepala sekolah SDN 4 Napabalano mulai melaksanakan beberapa kegiatan atau aktivitas tertentu untuk memenuhi kebutuhan guru dalam mengembangkan inovasi pembelajaran guru agar menghasilkan pembelajaran yang efektif dan stabil. Kebijakan tersebut dimulai dari

\section{1) Kepala Sekolah Yang Memenuhi Kebutuhan Guru.}

Ada banyak hal yang menjadi kebutuhan guru untuk dapat melaksanakan proses pembelajaran yang baik, inovatif dan kreatif seperti kurikulum, bahan ajar, sarana dan prasarana, media, serta mempunyai akses yang luas. Dalam hal ini, kepala sekolah berupaya untuk memenuhi kebutuhan tersebut melalui berbagai bentuk kebijakan antara lain melakukan pengembangan kurikulum yang melibatkan tim pengembang kurikulum sekolah (TPK), 
mengembangkan bahan ajar dengan melibatkan seluruh guru, peningkatan pemenuhan sarana dan prasarana dengan memaksimalkan penggunaan dana-dana bantuan pemerintah, pengembangan media pembelajaran, dan memperluas akses guru untuk dapat mendapatkan pengetahuan dari berbagai sumber baik sumber langsung (melalui pelatihan) maupun tidak langsung (internet). Dalam hal ini, tindakan yang dilakukan kepala sekolah telah mengadaptasi pemahaman bahwa salah satu faktor pendukung munculnya motivasi guru untuk menjadi lebih kreatif, inovatif, dalam meningkatkan kualitas pembelajaran adalah dengan adanya pemenuhan kebutuhan guru baik kebutuhan pribadi maupun kebutuhan profesional. Hal ini sejalan dengan hasil penelitian Poom-Valickis, \& Francesconi, (2017) yang menyatakan bahwa Analisis korelasi antara kebutuhan dasar dan motivasi akademik menunjukkan bahwa kebutuhan akan kompetensi dan kemandirian memiliki korelasi yang lebih tinggi dengan motivasi intrinsik $(r=0,44$ dan $r=$ $0,47, \mathrm{p}<0,01)$ dibandingkan keterkaitan $(\mathrm{r}=$ $0,28, \mathrm{p}<0,01)$.

Mark, A. (2015). Menegaskan bahwa faktor motivasi yang dapat menimbulkan kepuasan kerja guru di Sekolah Menengah Pertama Negeri Kabupaten Kibaha; temuan mengungkapkan bahwa guru sangat termotivasi untuk kepuasan mereka. Fakta bahwa tingkat kepuasan yang tinggi (di atas $65 \%$ ) pada masingmasing faktor / variabel yang terdaftar. Sehubungan dengan pertanyaan penelitian kedua dari penelitian ini, menurut temuan, pendapat responden ketika dirangking mengungkapkan bahwa faktor-faktor berikut adalah dianggap paling penting untuk ketidakpuasan kerja guru di sekolah menengah negeri Kabupaten Kibaha; Ini adalah kondisi kerja (38\%), manajemen dan administrasi (31\%), kesejahteraan guru (31\%), promosi kerja (28\%) dan persepsi masyarakat terhadap pengajaran $(34 \%)$. Hasil penelitian Mark tersebut sejalan dengan penelitian yang dilakukan oleh Hasanah (2020) yang menyebutkan bahwa salah satu faktor yang dapat meningkatkan kinerja guru adalah dengan memenuhi kebutuhan dasar guru agar para guru mendapatkan kepuasan kerja baik aspek jenis pekerjaan, lingkungan, maupun kebijakan kepala sekolah terkait gaji guru.

\section{2) Sistem Pendampingan Dalam Pengembangan Kompetensi Guru}

Kebijakan lain yang diterapkan kepala sekolah adalah dengan adanya pendampingan (guru tua dan guru muda) guna bisa berkolaborasi dalam menyelenggarakan ide-ide mereka, interaksi kepala sekolah dan guru untuk berdiskusi terkait permasalahan yang dihadapi guru pada proses pembelajaran. Hal ini merupakan ide yang sangat kreatif dari kepala seklah dalam rangka meningkatkan kreativitas dan inovasi pembelajaran dari para guru dengan memberdayakan kemampuan IT guru-guru muda untuk melakukan pendampingan terhadap guruguru yang senior, yang cenderung memiliki kelemahan dalam penggunaan IT. Kebijakan ini diambil karena faktanya di sekolah ada dua golongan kemampuan guru dalam memanfaatkan teknologi informasi yaitu guruguru milenial yang memiliki keahlian dalam penggunaan teknologi tinggi, sementara di sisi lain ada guru-guru yang sudah senior dan memiliki keterbatasan dalam menyesuaikan diri dengan perkembangan teknologi. Hal ini sejalan dengan hasil penelitian Baring, Rito \& Camarines, Teresa \& Cabatbat, Katherine Pia \& Reysen, Stephen. (2020) yang meyebutkan bahwa pendampingan guru tidak pernah dikhususkan dalam penelitian pendidikan sebagai konstruk yang independen dari variabel pendidikan lainnya. Ini sebagian menjelaskan mengapa Sebagian besar literatur menganggap pendampingan guru hanya dalam spektrum pembelajaran yang luas. Berbagai konsep diperkenalkan dalam penelitian untuk menggarisbawahi nilai kehadiran guru atau kualitasnya di lingkungan pembelajaran. Pendampingan guru dalam konteks ini pada dasarnya berinteraksi dengan perilaku mengajar yang menyebabkan berkuangnya stres dan pengalaman dukungan guru yang mendasari prestasi akademik dan pembelajaran

\section{3) Mengadakan Workshop}

Kepala sekolah mengadakan kegiatan (training, workshop) terkait penggunaan teknologi dan kegiatan lainnya untuk mengembangkan pembelajaran guru khususnya di masa pandemic covid-19 saat ini. Workshop dan pelatihan peningkatan kompetensi guru dalam penggunaan teknologi dlaksanakan secara 
daring dan menggunakan model coaching individual.

Program pelatihan membantu menghindari jebakan seperti perilaku buruk, kontrol yang berlebihan, penggunaan alat bantu pedagogis yang tidak tepat, PPT yang tidak tepat, blooper, dan moral yang menurun. Mereka mungkin juga berurusan dengan karyawan yang tidak puas. Program-program ini sangat membantu dalam memperkaya para pendidik dengan teknik, trik, tip, metode, proses dan prosedur baru, dan untuk menutup semuanya, inspirasi, memberi mereka kekuatan untuk menghadapi satu tahun akademik lagi. Bahkan aspek kecil seperti manajemen papan tulis/hitam, kehadiran panggung, postur, isyarat nonverbal (termasuk haptik, kinesik, kronemik), modulasi suara, interaksi, kepatuhan pada rencana pelajaran, persiapan dan pengurutan harus ditangani secara rinci dengan contoh dan anekdot yang sesuai. oleh pelatih yang kompeten. Program pelatihan komprehensif tentang Taksonomi Bloom, Gaya Pengajaran dan Pembelajaran, Pengembangan Kurikulum, Metode Penelitian dan Produksi Bahan sangat penting dan mungkin menjamin keterlibatan fakultas dari semua departemen (Santhanam Pillai, 2012).

4) Kepala Sekolah Melaksanakan Evaluasi Kegiatan Dan Mencari Solusi Pada Setiap Kelemahan Pembelajaran Yang Terjadi

Dalam hal ini kepala sekolah memahami bahwa untuk memenuhi kebutuhan dalam kondisi covid-19, para guru perlu ada tambahan keahlian terutama terkait penggunaan teknologi tinggi dalam pembelajaran. Ini menunjukan bahwa sebagai seorang pemimpin, kepala sekolah telah memahami pentingnya pelatihan dan pemberian keteramilan baru dalam rangka meningkatkan kompetensi guru agar guru lebih kreatif. Hal ini sejalan dengan hasil penelitian Trnova, Eva \& Trna, Josef. (2014) bahwa Kreativitas siswa dan guru memegang peranan yang sangat penting dalam pendidikan. Menurut para ahli, guru yang kreatif diperlukan untuk mengembangkan kreativitas siswa. Siswa harus merasa diharapkan untuk menjadi kreatif. Kaplan, Danielle. (2019). Menguatkan bahwa Kreativitas diperlukan untuk pemikiran inventif dalam domain apa pun, sehingga kreativitas perlu dikembangkan. Salah satu cara untuk mengembangkan kreativitas gruu adalah dengan memberikan pelatihan-pelatihan untuk para guru.

Kepala sekolah sangat memahami bawha langkah awal untuk menerapkan kebijakan baru pada pembelajaran tidak mudah, karena guru dan siswa dihadapkan dengan sesuatu yang baru. Salah satunya metode pembelajaran yang digunakan, penggunaan media yang sebelumnya hanya sekedar dikenal oleh siswa tetapi belum pernah dicoba dan itu butuh waktu untuk penyesuaian. Saat ini guru SDN 4 Napabalano sudah mulai menerapkan ide-ide yang mereka dapatkan pada pembelajaran, hasil akhirnya guru dan kepala sekolah mengevaluasi kembali untuk mencari solusi pada kelemahan dan mempertahankan kelebihan pada metode pembelajaran yang telah diselenggarakan. Hal ini sejalan dengan hasil penelitian Bichi, (2017), bahwa evaluasi kinerja guru adalah latihan yang terus menerus, rutin dan wajib dalam lingkungan pendidikan. Relevansinya dengan hasil belajar siswa dan akuntabilitas sekolah sangat besar dan tidak dapat diremehkan. Demikian pula, adalah fakta yang terkenal bahwa guru merupakan cerminan kualitas sekolah, sebab guru sebagai orang yang secara langsung mendidik anak-anak melalui proses pembelajaran yang mereka lakukan (Hasanah \& Supardi, 2020) Dalam hal ini, cara yang digunakan oleh kepala sekolah untuk menentukan efektivitas para guru di sekolah adalah melalui penilaian atau evaluasi, dimana supervise akademik dan evaluasi proses pengajaran secara langsung merupakan salah satu bentuk evaluasi yang terbukti efektif untuk menilai guru (Howard, 2018).

Kepala sekolah memiliki peran sebagai pemimpin di sekolah yang memiliki tanggung jawab penuh atas proses pendidikan, baik berkaitan dengan peningkatan profesionalisme guru dan semua yang berhubungan dengan sekolah (Sukmaswati, 2019), pendapat lain bahwa kepala sekolah juga merupakan sosok pemimpin yang memiliki kemampuan dan keterampilan yang diimplementasikan sebagai strategi dalam meningkatkan mutu pendidikan (Syafrizal, et al., 2016).

Selain beberapa hal yang disebutkan di atas, peran kepala sekolah pada tingkat sekolah, 
adalah sebagai evaluator, manajer, administrator, supervisor, leader, inovator dan motivator, beberapa istilah tambahan untuk menyebut jabatan kepala sekolah, seperti administrasi sekolah (shcool administrator), pimpinan sekolah (shcool leader), manajer sekolah (shcool manajer), dan lain-lain (E. Mulyasa, 2005). Jadi kepala sekolah merupakan pemimpin dalam suatu lembaga pendidikan dimana ia mengontrol, mengawasi dan mengarahkan semua warga sekolah untuk mencapai standar pendidikan nasional.

Sekarang ini masalah yang dihadapi oleh dunia pendidikan adalah menumbuhkan guru yang kreativitas. Kreativitas sangat penting, dengan adanya creative kita akan terdorong untuk mencoba berbagai macam cara dalam melakukan sesuatu (Saptono, 2016), searah dengan pernyataan berikut bahwa kreativitas dapat dikenali dan ditingkatkan melalui pendidikan yang tepat. Dalam hal pengajaran, pendidik merupakan objek kreativitas bagi peserta didiknya, dan begitu sebaliknya (Abdullah, 2016).

Adapun pentingnya kreativitas guru dalam pembelajaran antara lain: (1) Kreatifitas guru berguna dalam transfer informasi lebih utuh, (2) Kreatifitas guru berguna dalam merangsang siswa untuk lebih berpikir secara ilmiah dalam mengamati gejala masyarakat atau gejala alam yang menjadi objek kajian dalam belajar, (3) Produk kreatifitas guru akan merangsang kreatifitas siswa (Priatna, 2018). Jadi kreativitas guru merupakan kemampuan guru dalam menciptakan ideide baru saat mengajar sehingga memiliki variasi didalam mengajar yang membuat anak didik lebih aktif dan kreatif pula.

Dengan adanya kreativitas guru tersebut yang terus di kembangkan akan timbul inovasi. Pembelajaran dipandang sebagai kegiatan guru dalam desain instruksional untuk memfasilitasi siswa belajar dan dibutuhkan inovasi pembelajaran. Inovasi pembelajaran merupakan kegiatan-kegiatan terencana yang dikondisikan untuk mencapai tujuan pembelajaran (Priatna, 2018). Dari pernyataan berikut dapat diartikan bahwa inovasi pembelajaran merupakan aspek yang paling menentukan kesuksesan sebuah organisasi pendidikan dengan menggunakan metode-metode yang dilahirkan dari guru agar suatu pembelajaran dapat terlaksana dengan optimal.

Secara sederhana, kepemimpinan kepala sekolah dalam mengembangkan kreativitas guru dapat dilihat dalam gambar berikut ini:

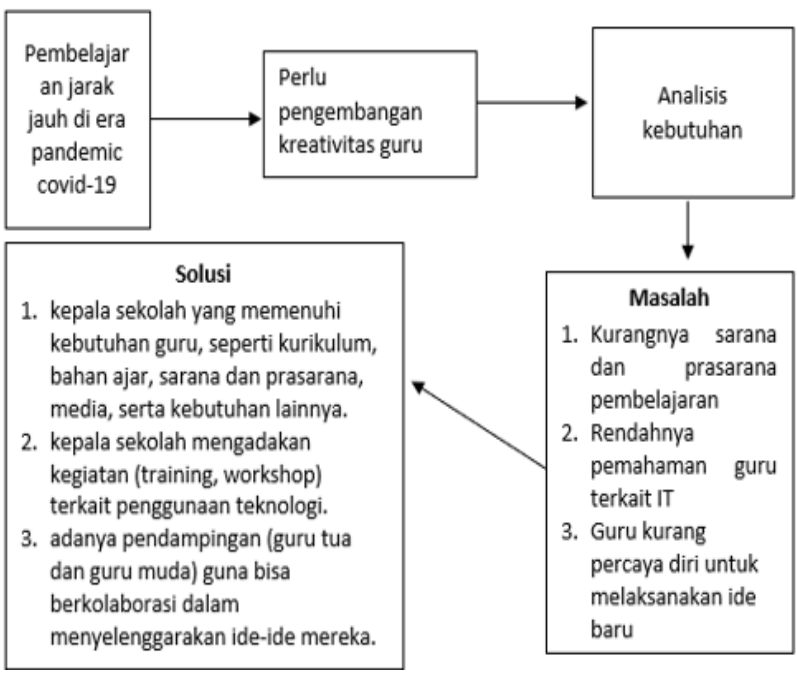

Gambar 1. Kepemimpinan kepala sekolah dalam mengembangkan kreativitas guru

\section{SIMPULAN}

Inovasi pembelajaran guru adalah upaya yang berkesinambungan guna memenuhi mutu pendidikan searah dengan perkembangan tuntutan masyarakat terhadap pendidikan. Untuk memenuhi upaya tersebut peran kepemimpinan kepala sekolah dibtuhkan untuk memenuhi kebutuhan pembelajaran guru, baik dari segi kurikulum, bahan ajar, sarana dan prasarana, media, serta mempunyai akses yang luas. Selain itu kebijaka yang diterapkan kepala sekolah dengan mengkolaborasikan guru (guru tua dan guru muda), menciptakan komunikasi yang baik antara guru dan kepala sekolah, serta mengikuti pelatihan-pelatihan untuk menambah wawasan terkait pembelajaran guru. Hasil penelitian ini menunjukan bahwa peran kepemimpinan kepala sekolah dalam meningkatkan kreativitas dan inovasi guru terjadi karena kepala sekolah selalu pro aktif dalam mengidentifikasi dan mengatasi berbagai permasalahan kontekstual yang terjadi di sekolah.

\section{DAFTAR PUSTAKA}

Akert, Nancy \& Martin, Barbara. (2012). The Role of Teacher Leaders in School Improvement through the Perceptions 
of Principals and Teachers. International Journal of Education, 4 (10), 5296/ije.v4i4.2290.

Çubukçu, Ceren \& Aktürk, Cemal. (2020). The rise of distance education during covid19 pandemic and the related data threats: a study about zoom. Conference: Online

International Conference of COVID-19 (CONCOVID)

Fitrah, M. (2017). Peran Kepala Sekolah Dalam Meningkatkan Mutu Pendidikan.

Penjamin $\quad$ Mutu, 3(1), 31. https://doi.org/10.25078/jpm.v 3i1.90.

Komalasari, K. (2010). Difusi Inovasi Pembelajaran Kontekstual dalam Pendidikan Kewarganegaraan. Julnal Ilmu Pendidikan, Vol. 17 (No. 3), 1-7.

Laihad, Hidayat, Rais. Yuyun El. Patras. Helena, G. (2018). 1*, 1 , 1 1. JMP Universitas PGRI Semarang, 7.

Lambriex-Schmitz, P., Van der Klink, M. R., Beausaert, S., Bijker, M., \& Segers, M. (2020). Towards successful innovations in education: Development and validation of a multidimensional Innovative Work Behaviour Instrument.

Vocations and Learning, 13(2), 313-340. https://doi.org/10.1007/s1218602009242-4

Moh. Rois, Fartika Ifriqia, D. S. (2017). Kepemimpinan Kepala Sekolah Dalam

Meningkatkan Kompetensi Guru. Edudeena, 1(2),592-597. https://doi.org/10.30762/ed.v 1i2.449

O'Connor, H. \& Gibson, Nancy. (2003). A StepBy-Step Guide To Qualitative Data Analysis. Pimatisiwin: A Journal of Aboriginal and Indigenous Community Health. 1. 63-90.

Puspitasari, E. (2016). Inovasi Pembelajaran Ilmu Pengetahuan Sosial. Edueksos :

Jurnal Pendidikan Sosial \& Ekonomi, $3(1), \quad 25-40$.

http://syekhnurjati.ac.id/jurnal/index.php/edueks os/article/view/324

Sonedi, S., Sholihah, T., \& Dihasbi, D. (2018). Peran Kepemimpinan Kepala Sekolah dalam Meningkatkan Kinerja Guru. Anterior Jurnal, 18(1), 13-22. https://doi.org/10.33084/anterior.v18i1. 436 Sukmaswati, I. (2019). Peran Kepala Sekolah. 347-355.

Wibowo, A., \& Saptono, A. (2017). Kepemimpinan Intrapreneurship, Budaya

Sekolah dan Kinerja Inovasi Guru. Jurnal Pendidikan Ekonomi Dan Bisnis (JPEB), 5(2) ,176193.https://doi.org/10.21009/jpeb.

005.2 .5

https://beritakotakendari.com/amp/2019/03/tahu n-ini-16-sekolah-di-munaakanmenjadi-sekolah-model/

Baring, Rito \& Camarines, Teresa \& Cabatbat, Katherine Pia \& Reysen, Stephen. (2020). Understanding Teacher Accompaniment in Schools: The Development and Validation of the Teacher Accompaniment Scale. AsiaPacific Social Science Review. 20. 77-87.

Poom-Valickis, Katrin \& Francesconi, Denis. (2017). Relations Between Student Teachers' Basic Needs Fulfillment, Study Motivation, And Ability Beliefs. 779-789. 10.15405 /epsbs. 2017.10.74.

Mark, A. (2015). Factors Influencing Teachers' Motivation and Job Performance in Kibaha District, Tanzania.Master Thesis, University of Tanzania. Retrieved on November 7, 2017 from http://repository.out.ac.tz/ 1413/1/Mark-

Agnes-DESSERTATION-24-11-2015.pdf

Hasanah, E.; Supardi, S. (2020). Effect of work environment and salary on private school teachers in Indonesia. Utopía y Praxis Latinoamericana, [S.1.], v. 25, p. 365-376, ago.ISSN 2477-9555. Disponible en: $<$ https://produccioncientificaluz.org/ind ex.php/utopia/article/view/ 33544>. Fecha de acceso: 19 dic. 2020

Trnova, Eva \& Trna, Josef. (2014). IMPLEMENTATION OF CREATIVITY IN SCIENCE TEACHER TRAINING. International Journal on New Trends in Education 
and Their Implications 1309-6249. 5. 54-63.

Kaplan, Danielle. (2019). Creativity in Education: Teaching for Creativity Development. Psychology. 10. 140-147. 10.4236/psych.2019.102012.

Santhanam Pillai, Deva. (2012). The Importance of Teacher Training in Professional Colleges. Conference: ICPOE 2012. Volume: ISBN 9788189843496

Bichi, Ado. (2017). Evaluation of Teacher Performance in Schools: Implication for Sustainable Development Goals. 2. 103-113. 